\title{
А.С. ИСАКОВ
}

аспирант кафедры архитектуры

Самарский государственный архитектурно-строительный университет

\section{ФАБРИКА-КУХНЯ В САМАРЕ АРХИТЕКТОРА Е.Н.МАКСИМОВОЙ}

\section{SAMARA FACTORY-KITCHEN by ARCHITECT E.N.MAXIMOVA}

Рассматривается соичильная трансформация быта советской семьи 1920-1930-х г2. и история создания зданий с типологией - фабрика-кухня. Излагается восстановление и поиск биографических материалов об авторе проекта самарской фабрики-кухни Е.Н. Максимовой. Описывается биография Е.Н. Максимовой и особенности архитектурно-планировочной организации фабрики-кухни в Самаре.

Ключевые слова: фабрика-кухня, архитектура, Максимова.

Город Самара находится в Европейской части России, является крупным промышленным и культурным центром Среднего Поволжья. В Самаре имеются выразительные и яркие объекты советского конструктивизма 1920-1930-х гг. Среди них: дом Промышленности, дом культуры им. Ф.Э. Дзержинского, штаб ПриВо и удивительный памятник конструктивизма - фабрика-кухня.

К середине 1920-х гг. в СССР при реализации социальных аспектов в жизни молодого государства требовалась совершенно отличная от старых стилевых направлений архитектура, которая, по мнению руководства и идеологов реводюции, отражала бы прорыв во всех сферах жизнедеятельности страны. Архитектура должна была на практике доказывать установившуюся модель устройства государства. Много работ проводияось по оптимизации жизни советского человека, созданию идеальной социалистической ячейки, рассчитанной на семью. Одним из путей оптимизации жизни человека представлялся путь создания крупных предприятий общественного питания, которые освободили бы женщин от тягот ведения домашнего хозяйства.

В те годы существовал лозунг освобождения женщин от «пут» домашнего хозяйства и вовлечения их в процесс строительства социалистического общества. Строительством фабрик-кухонь предлагалось решить вопрос как с общественным питанием для рабочих, так и с освобождением женщин от «кухонного» труда и превратить домохозяек в полноправных граждан советской республики.

Вопрос обеспечения качественным горячим питанием должен был быть решен с помощью строительства гигантов общественного питания - фабриккухонь, которые представляли собой крупные централизованные предприятия по приготовлению горячего питания. Фабрики-кухни строились в промышленных районах вблизи производственных зон и жилых кварталов.

Из организации, которая боролась с голодом в начале 1920-х гг. в стране, в 1923 г. по инициативе советского руководителя Халатова Артемия Багратовича
In the article social transformation of soviet family's everysay life in 1920-30s and history of buildings projecting with typology - factory-kitchen are considered. It says about the restoration and the search of biographic materials about the author of the factory-kitchen project in Samara E.N. Maximova. The article is writing about E.N. Maximova biography and the features of architecture - planning organization.

Key words: factory-kitchen, architecture, Maximova.

было организовано паевое товарищество «Народное питание» (Нарпит). Организация Нарпит занималась контролем и составлением заданий на проектирование зданий фабрик-кухонь. Архитекторы-инженеры данной организации формировали планировочные схемы, эскизные проекты в тесном контакте с ведущими проектными организациями, создавали новую типологию и отрабатывали архитектурностилистические особенности зданий фабрик-кухонь.

Одним из первых построенных объектов новой типологии стала фабрика-кухня, которая находится в центральной части Самары, на пересечении проспекта Масленникова и ул. Ново-Садовой. Сейчас ведется большая общественная работа по сохранению фабрики-кухни, так как этот памятник советской архитектуры находится под угрозой уничтожения. Идет пропаганда стилистических и симводических особенностей этого здания. Архитектурно-планировочная структура объекта уникальна. В плане она имеет очертания символа советского государства - «серп и молот». Этот факт вызывает неподдельный интерес как у профессионального сообщества архитекторов и краеведов, так и горожан в целом.

Существовал научный интерес к личности автора, запроектировавшей данное здание. Бытовало много неподтвержденных иегенд и историй, связанных с судьбой этого архитектора.

Первоначально были известны лишь имя и фамилия автора проекта, женщины-архитектора - Екатерина Максимова. В процессе исследования архивных чертежей проекта фабрики-кухни, датируемых 1930 г., хранящихся в архиве ГАСО, было выявлено, что в штампе проектной организации стоит подпись - Е.Максимова.

После анализа обширного материала первый серьезный результат дала обнаруженная книга - «Первые женщины инженеры», в которой найдена запись на с. 206: «Максимова Екатерина Николаевна. Приёма 1909 г. Инженер-архитектор. Работала главным архитектором строительного отдела московского центрального универмага. Стаж работы 11 лет. Трагически погибла в Москве в 1932 г.». 
Эта краткая биографическая заметка дала два существенных направления дальнейшего поиска. Стаио известно отчество архитектора, предварительно установлено место учебы - «Санкт-Петербургские женские политехнические курсы».

В декабре 2009 г. была осуществлена поездка в Москву, в результате которой на Ваганьковском кладбище была найдена могила Максимовой Екатерины Николаевны. Это место, где хоронили достойнейших людей своего времени. Оно входит в число национальных усыпальниц, что также свидетельствует о неординарной личности Е.Н.Максимовой.

В начале мая 2010 г. удалось связаться с родственниками Е.Н. Максимовой. Внучка Максимовой, Екатерина Никитична, посетив могилу и увидев оставленный для нее трафарет, обратилась в администрацию кладбища и связалась с исследователем. В результате, установив контакт с родственниками в мае 2010 г., была осуществлена третья поездка в Москву.

Как выяснилось, родственниками оказались внуки Е.Н. Максимовой - Екатерина Никитична и Павел Никитич, с которыми состоялась встреча. В ходе личной беседы были получены уникальный биографический материал и некоторые сохранившиеся документы.

Максимова Екатерина Николаевна родилась 12 декабря 1891 г. в городе Казани, в православной семье. Ее родители были глубоко верующие люди. Отец, имевший частицу татарской крови и свободно владевший татарским языком, работал учителем в национальной татарской школе, готовившей ремесленников. По семейной легенде фамилия звучит как Максимов. С башкирского иди с татарского Максус - означает особый, особенный. Уже позднее, после принятия православия, стали Максимовыми. Весь их род был из Башкирии, из-под города Стерлитамака.

После успешного окончании Казанской художественной школы Екатерина Николаевна решила связать свою профессиональную жизнь с архитектурой. В 1910 г. она подала документы во Второй Петроградский Подитехнический Институт. К этому моменту ее родной старший брат Владимир Николаевич уже приступил к работе архитектора в Санкт-Петербурге, где он закончил Высшее художественное училище при Академии художеств.

Е.Н. Максимова в 1910 г. поступила на Архитектурный факультет Второго Петроградского Политехнического Института и с отличием его закончила, выполнив дипломную работу на тему: «Гостиница - Санаторий».

В 1914 г. Е.Н. Максимова участвовала в проектировании земского дома в Киеве. В трудовой книжке с этого года введется отсчет ее профессиональной деятельности.

В дальнейшем, в период с 1915 по 1918 гт., она работала в качестве помощника архитектора по проектированию и производства у раздичных архитекторов Санкт-Петербурга.

В 1918 г. участвовала в составлении раздичной проектной документации для строительства в Санкт-Петербурге.
В 1923 г. Максимова приезжает в Москву. Ее брат Владимир Николаевич до революции активно сотрудничал и помогал в ряде проектов академику архитектуры А.В. Щусеву, в результате чего Екатерина Николаевна получила возможность поработать с А.В. Щусевым в проектировании Казанского вокзала. И с 1923 по 1925 гг. она активно трудилась в составе проектного подразделения на строительстве Казанского вокзала.

С 1925 г. Е.Н. Максимова переходит на должность инженера-архитектора в Нарпит и вместе с вновь организованной группой инженеров, архитекторов, технологов начинает с чистого листа разрабатывать идеологию проектирования объектов с особой функциональной задачей - общественное питание, в дальнейшем получивших название фабрики-кухни. Она внесла огромный вклад в дело проектирования фабрик-кухонь в СССР. Постоянно ездила в командировки, с ее участием составлялись проекты московских фабрик-кухонь, на Днепрострое, в Екатеринбурге, в Магнитогорске и во многих других городах страны. Одной из последних построенных по ее проекту фабрик-кухонь была самарская, которая синтезировала в себе все те многолетние наработки функционально-планировочного зонирования данных объектов и их архитектурных воплощений.

Судьба Максимовой сложилась трагически. Блестящие результаты на работе, уже обустраивающийся быт в семье архитектора, - но все оборвалось в одночасье: она погибла в марте 1932 г., попав под поезд. Трагическое стечение жизненных обстоятельств не дало ей возможности увидеть при жизни свой наиболее самобытный, талантливый и очень символичный проект - Самарскую фабрику-кухню.

По сфабрикованному делу в апреле 1932 г. был арестован брат Максимовой Владимир Николаевич. Он был глубоко верующим человеком, до революции занимался проектами для семьи Романовых в Царском селе. Император Николай II был крестным отцом у сына Максимова Арсения. Государственная политика и борьба с церковью приведи к тому, что в 1932 г. была объявлена пятилетка безбожия. ОГПУ весной 1932 г. провело операцию «пасхальный набор», в результате которой многие священнослужители были арестованы. Владимир Николаевич был причислен к тайной православной организации «Истинно православная церковь», в результате на него и сына был выписан ордер на арест. Максимова настолько искренне поверила в возможность свершения тех социальных преобразований в стране, что честно и талантливо трудилась. Обстоятельства гибели Екатерины Николаевны очень запутанны. Было ли это несчастным случаем или нет, сейчас говорить сложно. В тот день она с проектами возвращалась домой в посеиок Кратово. Спустя месяц после ее гибели, в дом пришли сотрудники ОГПУ и предъявили ордер на арест Максимовой Екатерины Николаевны, брат уже к тому моменту отбывал заключение. В ответ родственники сообщили, что Максимова погибла и арестовывать некого. 
Вскоре после трагической гибели Екатерины Николаевны, на Ваганьковском кладбище сотрудниками Нарпита ей был установлен памятник.

Рассмотрим и проанализируем проект Самарской фабрики-кухни Е.Н. Максимовой, который был принят к реализации. Объект был запроектирован на отведенном участке, на пересечении ул. Ново-Садовой и нынешнего проспекта Масленникова. По предложенному Максимовой варианту градостроительного расположения объекта, дуга обеденных залов и развитой вестибюльной группы была обращена к углу ул. НовоСадовой и проспекта Масленникова. Она входила в рукоятку молота, которая собирала в себе производственные помещения кухни. Это градостроительное расположение было утверждено и реализовано.

План 1-го этажа на отм. 0.000 м представляет собой трехчастное деление дуги, с вестибюлем и гардеробом в центральной части. В левой части дуги от вестибюля располагался детский обеденный зал с дополнительным входом, в правой части дуги - обеденный зал. В прямой части молота, в так называемой рукоятке, располагались почта и помещение магазина. У них был организован отдельный вход с улицы. В дворовой части, в продолжении молота, находились производственные и подсобные помещения кухни.

На 2-м этаже на отм. 4.200 м в дуге были расположены последовательно три обеденных зала, начиная с детского и заканчивая залом приема пищи для персонала. В рукоятке молота находились помещения персонала, технологические помещения, горячий цех и др. Из округлой части молота, где располагался горячий цех кухни, пища доставлялась по трем переходам, которые входили в технологический коридор дуги, примыкающей к обеденным залам, откуда осуществлялась раздача готовых обедов.

Кровля над дугообразным корпусом была односкатной, с уклоном во внутренний двор, за высоким фасадным парапетом. Над прямоугольным объемом молота кровля была двухскатной, торец молота скрывался за высоким фасадным парапетом, который сохранился и в наше время. Между двумя центральными лестницами по дуге была устроена летняя терраса для обедов на открытом воздухе.

Вертикальные связи осуществлялись по 6 лестницам, 3 из которых были парадными и находились непосредственно в системе обеденных залов дуги здания. Они также очень четко завязаны с пространственными переходами, связывающими корпус - «молот» и корпус - «серп». По проекту Максимовой предполагалось, что посетитель, сдавший одежду в гардероб, воспользуется одной из двух больших парадных лестниц.

Горизонтальные технологические связи осуществлялись по переходам второго этажа, связывавшим производственную часть кухни с обеденной зоной. Вертикальные технологические связи между обеденными залами и производственными частями кухни осуществляли 7 подъемников.

Основные принципы в решении фасадов были отражением самых передовых достижений в архитектуре и строительстве 1920-1930-х гг. Был использован рационадьный подход к решению конструкций и фасадных плоскостей, отсутствовали декоративные детали. Акцентом на главном фасаде служила входная группа, организованная между иест- ничными объемами, которые на всю высоту были остеклены. Над входной группой консольно нависал обеденный зал второго этажа. По всей дуге первого и второго этажа были запроектированы большие горизонтальные проемы с узкими простенками, которые “западали” вместе с витражами и были выкрашены в темно-серый цвет. Эти решения имитировали сплошное ленточное остекление. Выступающие широкие горизонтальные массивы под витражом и над ним объединяли витражное остекление в единую непрерывную ленту. Пространственные переходы из производственной части «молота» в «дугу» обеденных залов также были остеклены витражами с определенными членениями. Переходы опирадись на колонны, выполненные из бетона. Колонны переходов сохранились в неизменном виде до наших дней. При внимательном анадизе их исподнения приходим к выводу о том, что подобные приемы сооружения бетонных элементов здания встречаются в России в лучших образцах конструктивизма.

Архитектору Е.Н. Максимовой и самарским строителям удалось создать уникальный пример конструктивистской архитектуры. Здание, подобно большой отлаженной машине, с четким делением функциональных процессов, протекающих в теле фабрики-кухни, было авангардным по своему объемно-планировочному решению. К этому можно отнести и вертикальные связи, которые организованы в лестничных блоках при помощи техноиогических подъемников. Организованная система перемещения персонала и посетителей объекта исключала возможность пересечения потоков.

Передовые архитектурные идеи и отставание технологий в строительстве в России в 1930-е гг., а именно в производстве витражных конструкций с имитацией сплошного остекления, привели к тому, что фабрика-кухня подверглась в дальнейшем серьезным изменениям. Но весь конструктив здания, бетонный каркас и перекрытия остались в неизменном виде. В 1944 г. по проекту самарского архитектора И.Г.Салоникиди было предложено классическое оформление фасадов. Задача, которая ставилась перед архитектором, заключалась в уменьшении теплопотерь здания. С архитектурной точки зрения, было необходимо придать объекту классический вид. В результате совместили конструктивистскую основу объекта и классические формы. В ходе реконструкции фасадов были заложены три центральные лестницы, которые были остеклены витражами на всю высоту. В них появились обычные оконные проемы. Были уменьшены размеры всех витражных проемов по периметру здания, на первом этаже появились классические горизонтальные русты. Был заложен центральный вход и организован вход непосредственно в иестничные клетки, что, конечно же, очень упростило архитектурное решение.

В 1999 г. здание было обшито пластиковым сайдингом, и в бывшей фабрике-кухне был организован торговый центр «Пассаж».

В наше время пластиковый сайдинг демонтирован, вместе с ним была утрачена оригинальная надпись на торце «молота» - «ФАБРИКА-КУХНЯ». Здание не функционирует. В зимний период объект не отапливается, что ведет к его постепенному разрушению. 


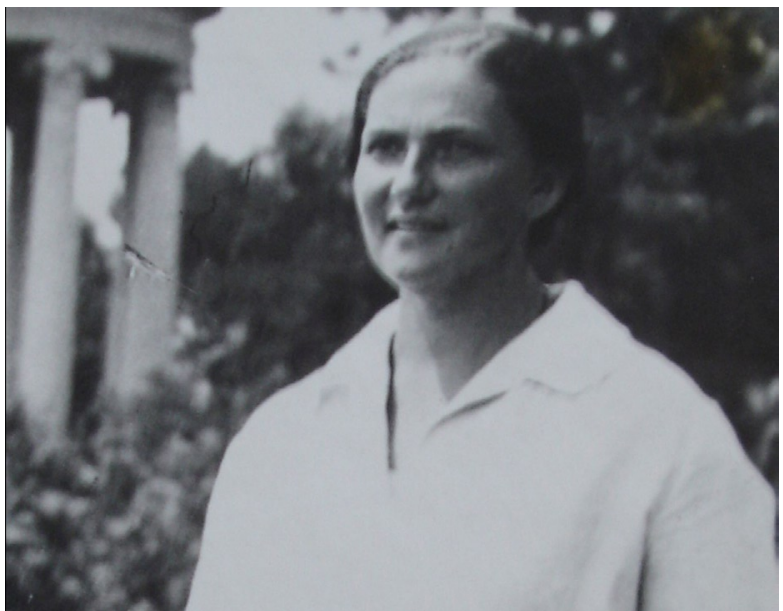

Архитектор Самарской фабрики-кухни Е.Н.Максимова
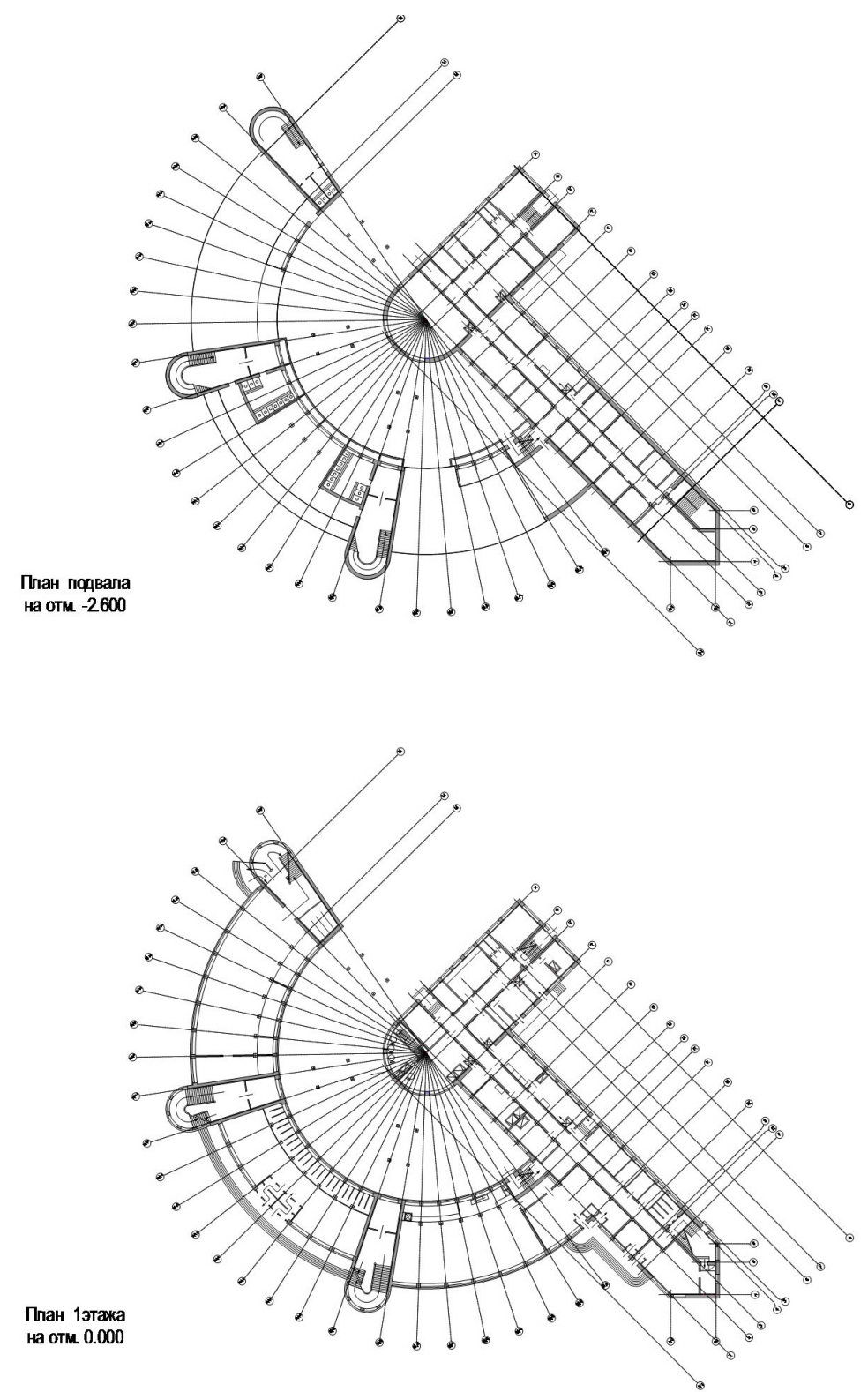

Графическая реконструкизия планов 

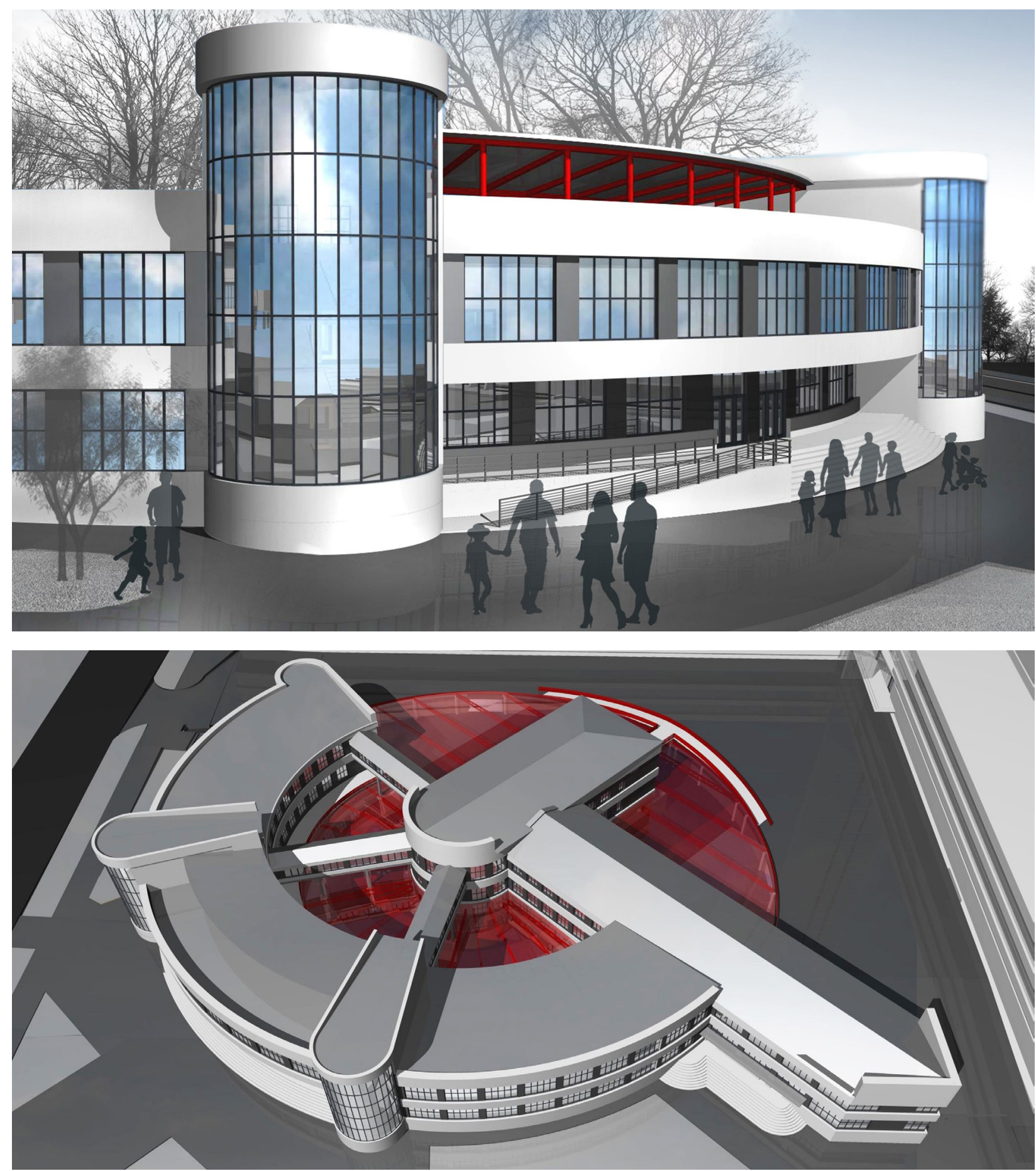

3D модели реконструкциии первоначального облика Самарской фабрики-кухни

БИБЯИОГРАФИЧЕСКИЙ СПИСОК

1. Первые женщины - инженеры [Текст] / сост.: В.П. Богомазова, Т.Д. Каценеленбоген, Т.Н. Пузыревская. - Д., 1967.

2. 81 архитектурный шедевр [Текст] / В.Э Стадников, О.А. Федоров. - М., 2006.

3. Самара: наследие под угрозой [Текст] / сост.: В. Стадников , С. Клементина.,А. Гозак. - Самара, 2009.

4. Дичный архив семьи Максимовых.

(C) Исаков А.С., 2011 